\title{
Versiones del Trauma: LaCapra, Caruth y Freud Versions of the Trauma: LaCapra, Caruth and Freud
}

\author{
Luis Sanfelippo \\ Instituto de Investigaciones, Facultad de Psicología \\ Universidad de Buenos Aires. Argentina \\ luissanfe@gmail.com
}

\begin{abstract}
This article sheds light on the concept of "trauma" present in some passages of the works of Dominick LaCapra and Cathy Caruth, and their debts with Sigmund Freud's conceptions. It also examines the specific proposals of the Viennese intellectual, which can help avoid a purely descriptive use of that concept. Special attention has been paid to the way these authors conceive memory and time, and to potential uses of the concept of trauma for some historical cases.
\end{abstract}

\section{Key Words}

Trauma, repression, literality, nachträglich, economic perspective.

\section{Resumen}

El presente artículo examina el concepto de "trauma” presente en algunos pasajes de las obras de Dominick LaCapra y Cathy Caruth, así como sus deudas con las concepciones de Sigmund Freud. También se estudia las propuestas específicas del intelectual vienés, que pueden a ayudar a evitar un uso puramente descriptivo de dicho concepto. Se ha prestado especial atención al modo en dichos autores conciben la memoria y la temporalidad, y a algunos usos potenciales del concepto de trauma para ciertos casos históricos.

\section{Palabras claves}

Trauma, represión, literalidad, nachträglich, perspectiva económica. 
En las últimas tres décadas, la noción de trauma ha ganado cierto lugar en la historiografía y en las ciencias sociales interesadas por procesos históricos propios del pasado reciente. En ocasiones, la utilización de dicha categoría se limita a un uso meramente descriptivo, el adjetivo "traumático", que calificaría ciertas experiencias como disruptivas, que conmocionan. Pero no son pocos los autores que se han apropiado de esa y otras nociones provenientes del psicoanálisis (en particular) y de la psicopatología (en general) y las consideran herramientas imprescindibles para la comprensión de la historia contemporánea posterior a la Shoah. Entre ellos se destacan Dominick LaCapra y Cathy Caruth. Para el primero, el trauma constituye "un problema crucial para el pensamiento moderno", y la adopción de “conceptos psicoanalíticos (para) la indagación histórica” sería imprescindible "para dilucidar qué es el trauma y cuáles son sus repercusiones en la cultura y en la gente." 2 Para la segunda, “en una era de catástrofes, como es ésta”, ${ }^{3}$ los traumas transmitirían una "verdad” no sólo personal sino histórica, ligada a una "crisis de la verdad" de las narraciones históricas, vinculada con los límites de la experiencia y del conocimiento histórico. ${ }^{4}$

El valor ejemplar de los planteamientos de estos autores no radica tanto en la utilización de esas categorías para el estudio de experiencias históricas concretas, sino en la reflexión y la teorización que han realizado sobre el lugar del trauma en la historia contemporánea. Groseramente podría pensarse que sus ideas resumen e ilustran las concepciones sobre el trauma implícitas en muchas de las investigaciones históricas sobre casos particulares.

Si bien las perspectivas adoptadas por ambos autores convergen en la importancia otorgada al trauma dentro de la historia contemporánea, y en la apropiación de categorías provenientes del discurso "psi” para usarlas como herramientas que permitan pensar el pasado reciente, dichas perspectivas también presentan diferencias. Sobre todo, respecto al modo en que cada uno concibe la memoria y la temporalidad que estaría implicada en los procesos traumáticos, así como también en la lectura que realizan de los trabajos de Sigmund Freud relacionados con el tema. Cada uno de ellos encuentra en la pluma del psicoanalista vienés la ocasión para centrar la problemática del trauma o bien en torno a la represión del pasado y su retorno repetitivo (LaCapra) o bien en relación con la reiteración literal, no narrativa, del evento traumático (Caruth). Estos sesgos de lectura presentan problemas no sólo porque se refieren a la noción freudiana de "trauma" en singular, como si se tratara de un objeto invariable y de una categoría unívoca, en lugar de abordarlo a partir de sus distintas conceptualizaciones que recortan diferentes problemas o experiencias, sino también porque, en su utilización en el terreno de la historia, corren el riesgo de reducir todos los casos singulares a una misma grilla interpretativa, que encontraría el retorno de lo reprimido o la reiteración de lo literal en cada experiencia histórica calificada de traumática.

\footnotetext{
${ }^{1}$ Dominick LaCapra, Escribir la historia, escribir el trauma (Buenos Aires: Nueva Visión, 2005), 17.

${ }^{2}$ Ibid.

${ }^{3}$ Cathy Caruth, Trauma: Explorations in Memory (Baltimore: The Johns Hopkins University Press, 1995), 11.

${ }^{4}$ Ibid., 8.
} 
En el presente artículo intentaremos analizar con mayor detalle las posiciones de LaCapra y Caruth respecto de la memoria y de la temporalidad del trauma en la historia. En la parte final nos detendremos en el análisis de dos conceptualizaciones divergentes sobre ambas aristas que se hallan presentes en la obra de Freud. Como hemos señalado en otra ocasión, ${ }^{5}$ es posible ubicar en los textos del psicoanalista múltiples configuraciones conceptuales sobre el trauma, que responden a distintos modelos epistémicos y recortan diferentes figuras de lo traumático. En esta ocasión, ordenaremos las ideas del mismo autor sobre este tema a partir de dos concepciones disímiles que, a pesar de las apariencias superficiales, no coinciden con las posiciones respectivas de los autores norteamericanos. Por un lado, una configuración centrada en la temporalidad nachträglich, que no consiste en la represión y el retorno de lo reprimido sino que funciona como la condición de posibilidad para que estos procesos tengan lugar. Por otro lado, una perspectiva económica que circunscribe una ruptura abrupta de la continuidad temporal y de la posibilidad de rememoración de la experiencia, pero que estaría en las antípodas de una conservación "literal" de lo ocurrido. Al mismo tiempo, intentaremos destacar algunas posibilidades y problemas que estas concepciones han abierto en los usos concretos y potenciales en el terreno de la historiografía.

\section{LaCapra y el retorno de lo reprimido}

En los textos de LaCapra, el trauma y la repetición del mismo por parte de quienes lo han vivido (denominada por él acting out postraumático) quedan asociados entre sí de un modo tal que no parece posible concebir el uno sin la otra. En sus propias palabras:

\section{El trauma se produce oscuramente a través de la repetición, pues el acontecimiento lentamente traumático no se registra al momento de su ocurrencia sino sólo tras una brecha temporal o período de latencia, que en su momento es inmediatamente reprimido, desplazado o negado. Entonces de algún modo el trauma ha de retornar compulsivamente como lo reprimido. ${ }^{6}$}

En esta extensa cita puede apreciarse cómo el foco del autor se desliza desde la situación primera hasta su repetición, donde el trauma tendría lugar por el retorno de lo que fue en su momento reprimido. De esta manera se pasa por alto el análisis de las condiciones que podrían volver traumática a una experiencia: ${ }^{7}$ sólo queda subrayado que tras el acontecimiento (T1) ocurrió una represión (R) que inauguró un período de latencia (T2) que culmina con el retorno de lo reprimido (T3), sin que tampoco se interroguen las razones por las que el evento pretérito olvidado sale de su letargo.

\footnotetext{
${ }^{5}$ Luis Sanfelippo, "La noción de trauma. Apuntes para una interlocución entre el psicoanálisis y la memoria social”, en Inconciente e historia después de Freud. Cruces entre filosofía, psicoanálisis e historiografía, ed. Omar Acha y Mauro Vallejo (Buenos Aires: Prometeo, 2010), 119-134.

${ }^{6}$ Dominick LaCapra, Representar el Holocausto. Historia, teoría y trauma (Buenos Aires: Prometeo, 2008), 188.

${ }^{7}$ Problema que consideramos crucial. ¿Por qué una experiencia deviene traumática? ¿Qué nos autoriza a pensar una vivencia o un aspecto de ella como trauma? De no precisar esta cuestión se corre el riesgo de extender el término a toda situación no placentera. Indudablemente, una categoría que pretende explicar tanto, desde los hechos más horrorosos que escapan al entendimiento hasta las circunstancias más banales que producen desagrado, probablemente termine no explicando nada.
} 
Lo que sí se explicita es que el pasado no regresaría bajo la forma de un relato sino de un actuar, en el cual el presente y el futuro quedarían subsumidos y determinados por aquél. "En el acting out, los tiempos hacen implosión, como si uno estuviera de nuevo en el pasado viviendo otra vez la escena traumática." 8 Serían "situaciones en las que el pasado nos acosa y nos posee, de modo que nos vemos entrampados en la repetición compulsiva de escenas traumáticas, escenas en las que el pasado retorna y el futuro queda bloqueado o atrapado en un círculo melancólico y fatal que se retroalimenta." "Para salir de esta indistinción temporal determinada absolutamente por el tiempo pretérito, la solución radicaría en la posibilidad de "elaboración”. "En la medida en que elaboramos el trauma (...) nos es posible distinguir entre pasado y presente, y recordar algo que nos ocurrió (o le ocurrió a nuestra gente) en aquel entonces, dándonos cuenta empero de que vivimos aquí y ahora, y hay puertas hacia el futuro."10

Vale la pena comentar varios aspectos de estas citas. En primer lugar, el carácter problemático de la oposición que queda armada entre acting out y elaboración. Si bien LaCapra aclara que alcanzar la elaboración "no implica ni que exista una oposición neta entre el pasado y el presente ni que el acting out pueda superarse plenamente", ${ }^{11}$ el establecimiento de este par de oposiciones sugiere que, en el caso del acting out, el presente sería tan sólo el lugar donde el pasado retorna y se impone, el sitio donde vendría a alojarse una escena del pasado que dominaría completamente la situación actual. Si en un tiempo primero (T1), se produjo la escena traumática (E1), que luego fue reprimida (R), inaugurando un periodo de latencia (T2), cuando ésta llega a su fin por el retorno de lo reprimido (T3) se repetiría esa misma escena (E1), como si el contenido de lo acontecido en esa instancia posterior sólo estuviera determinado por el pasado.

$$
(\mathrm{T} 1 / \mathrm{E} 1) \longrightarrow(\mathrm{T} 2) \longrightarrow(\mathrm{T} 3 / \mathrm{E} 1)
$$

Ahora bien, el par de opuestos acting out / elaboración se inspira y sustenta en el texto "Recordar, repetir y reelaborar" de Freud. ${ }^{12}$ En dicho artículo Freud afirma que, durante el tratamiento, "el analizado no recuerda, en general, nada de lo olvidado y reprimido, sino que lo actúa. No lo reproduce como recuerdo, sino como acción; lo repite sin saber, desde luego, que lo hace."13 Como puede apreciarse, la "actuación”, si bien es concebida como la repetición de un pasado reprimido, no se opone a la elaboración sino al "recuerdo". Al mismo tiempo, dicha actuación/repetición se presenta, para Freud, "como resistencia a todo recordar." ${ }^{14} \mathrm{Si}$ actuar toma la función de una resistencia a autorizar el acceso a la memoria consciente de un fragmento del pasado, entonces la repetición no estaría sólo determinada por el tiempo pretérito sino también por las condiciones "presentes", es decir, por las instancias represoras para quienes ese fragmento otrora olvidado, que puja por salir a la conciencia, sigue siendo "conflictivo". Por ende, si hay un

\footnotetext{
${ }^{8}$ Dominick LaCapra, Escribir la historia, 46.

${ }^{9}$ Ibid., 45-46.

${ }^{10}$ Ibid., 46.

${ }^{11}$ Ibid.

${ }^{12}$ Sigmund Freud, “Recordar, repetir y reelaborar”, en Sigmund Freud, Obras completas, trad., ed. José Luis Etcheverry, 25 vols. (Buenos Aires: Amorrortu, 1986), Vol. 12.

${ }^{13}$ Ibid., 151-152.

${ }^{14}$ Ibid., 152.
} 
cierto grado de indistinción temporal en la repetición, no es por una determinación plena del pasado: lo que ocurre en el presente (T3) depende tanto de la escena primera como de la posición de resistencia a ésta en la que se ubica el sujeto en la actualidad (E1+Res).

En segundo lugar, así como el actuar se define en un vínculo de oposición al recordar, en el texto freudiano la elaboración queda enlazada con la resistencia (y no con el acting out). Si el psicoanálisis apunta, en líneas generales, a propiciar el recuerdo de lo que ha caído en la represión, lograr esa meta supondría el "vencimiento de la resistencia (que) comienza (...) con el acto de ponerla en descubierto." "Sin embargo, para Freud "nombrar la resistencia no puede producir su cese inmediato. Es preciso dar tiempo al enfermo para enfrascarse en la resistencia, no consabida para él; para reelaborarla (durcharbaiten)" ${ }^{16}$ Es cierto que, en la perspectiva del psicoanalista vienés, el carácter forzoso, compulsivo de la repetición, se debe a la fuerza de las mociones pulsionales reprimidas. Parte de la resistencia a recordar podría ser pensada entonces como una negativa a resignar una vía de satisfacción delineada en el pasado. Pero también la resistencia consiste en una negativa a permitir el recuerdo consciente de lo que hoy continúa siendo fuente de conflicto. Por ende, el punto a elaborar no sería tanto el acting out, la repetición del pasado (como sugiere LaCapra), sino la resistencia presente a recordar aquello que no se condice con la trama de representaciones actuales. En otras palabras, aceptar el pasado como tal (en lugar de repetirlo como actual) supondría para Freud modificar el presente.

Por otro lado, en la perspectiva de LaCapra lo que retorna de lo reprimido y se repite es una escena. Es decir, algo que, si bien fue olvidado y no forma parte de las narraciones conscientes, tampoco posee un carácter tal que impida su transformación posible en un relato. Por el contrario, el término "escena" refuerza la idea de una trama representacional que delinea un escenario donde una acción tiene lugar, siendo el todo completamente compatible con narraciones que pudieran sustentar la memoria de ella. En ese punto, el pensamiento de LaCapra parece distinguirse de las concepciones de Caruth y de algunos pasajes de Freud sobre el trauma y la memoria. Él mismo se pregunta "¿en qué medida el trauma o la 'vivencia' traumática quiebran la experiencia y plantean problemas específicos para la representación y la escritura?"17 A ese interrogante se podría responder que en su carácter de escena el trauma podría ordenar la experiencia pero no quebrarla, determinar lo posible en el presente a partir del pasado, pero sin que ello introduzca una ruptura con lo representable. ${ }^{18}$ Esa escena ya estaría "escrita”, aunque conservada en otro lugar, distinto al de las representaciones conscientes. Ahora bien, es justo decir que hay otros pasajes de LaCapra que parecen incluir los límites de la representación y de la apropiación del pasado por las memorias presentes. Por ejemplo, la idea de una existencia de "restos traumáticos

\footnotetext{
${ }^{15}$ Ibid., 156.

${ }^{16}$ Ibid., 157.

${ }^{17}$ Dominick LaCapra, Escribir la historia, 60.

${ }^{18}$ Además, por momentos, la referencia a una escena traumática es tomada globalmente, como si toda la escena fuera traumática. Así ocurre cuando algunos autores consideran que el nazismo o la última dictadura argentina deben ser caracterizados en su conjunto bajo el signo del terror. Esto impediría ver que hubo algunos aspectos del funcionamiento estatal y de la vida cotidiana durante esos procesos que conservaron ciertas formas de continuidad y normalidad, contando con la aceptación y/o la complicidad de buena parte de la sociedad civil. Y, más importante aún, dificulta delimitar cuáles son los elementos específicos (campos de concentración, desaparecidos, etc.) de esas experiencias que podrían ser calificados de traumáticos.
} 
que resisten el poder potencialmente curador del trabajo de la memoria."19 Podría interpretarse que tales restos serían para él puntos que denotarían una elaboración aún no concluida. Sin embargo, la oposición del autor a lo que él llama narraciones "fetichistas" (que serían aquellas que intentan negar las pérdidas y reconstruir identidades homogéneas, sin diferencias ni conflictos), conduce a pensar que esos restos traumáticos serían ineliminables. En esa línea, el autor plantea que "ante un trauma severo, una de las exigencias de la elaboración sería el reconocimiento activo de que no todo puede ser elaborado., 20

Por último, quisiéramos destacar el acercamiento que realiza LaCapra entre trauma y pérdida, lo que le conduce a acercar la elaboración con el duelo. Por momentos, éste último y "los distintos modos de pensamiento y quehacer crítico" aparecen como algunos de los procesos de elaboración. ${ }^{21}$ La conexión entre elaboración y duelo no es planteada explícitamente por Freud, aunque puede quedar sugerida por los términos elegidos por el psicoanalista vienés para referirse al "trabajo de duelo"22 y la elaboración (durcharbaiten), que tanto en alemán como en su traducción inglesa (working-through) remiten mucho más claramente a la necesidad de un proceso trabajoso que el propio término elegido para la traducción castellana.

Por otro lado, la cuestión de la pérdida se inserta en los textos de LaCapra en el contexto de una diferenciación (necesaria) de otras categorías como ausencia y falta. ${ }^{23} \mathrm{El}$ propósito principal del autor es evitar que las pérdidas (históricas, contingentes, evitables) sean equiparadas a las ausencias (estructurales, necesarias) y, entonces sacralizadas, justificadas y consideradas irreparables.

Pero, en estos movimientos, se desliza que un trauma sería, sobre todo, una pérdida. Efectivamente, podría pensarse que ciertas pérdidas pueden ser traumáticas, aunque, claro está, no podrían ser todas, salvo al precio de extender tanto la categoría de trauma como para quitarle cualquier poder explicativo. Al mismo tiempo, algunas experiencias susceptibles de ser pensadas como traumas parecen prescindir de la existencia de una pérdida. De todos modos, podríamos preguntarnos si lo que vuelve traumática a una experiencia e, incluso, a una pérdida no reside, más bien, en lo que permanece presente. Aquello que del trauma genera problemas y controversias en el campo de la memoria y la temporalidad, ¿reside en lo que ya no está? ¿o más bien debería ser ubicado en lo que se resiste a perderse y cuya presencia conmociona la experiencia? Retomaremos este punto más adelante, al abordar algunos pasajes de la perspectiva económica del trauma en Freud.

\section{Caruth y la reiteración "literal” del trauma}

\footnotetext{
${ }^{19}$ Dominick LaCapra, Historia y memoria después de Auschwitz (Buenos Aires: Prometeo, 2009), 208.

${ }^{20}$ Ibid., 233.

${ }^{21}$ Dominick LaCapra, Escribir la historia, 46.

${ }^{22}$ Sigmund Freud, “Duelo y Melancolía”, en Sigmund Freud, Obras completas, Vol. 14, 242.

${ }^{23}$ Dominick LaCapra, Escribir la historia, 65-103.
} 
Como hemos visto, la concepción de LaCapra sobre el trauma se sustenta en el retorno de una escena del pasado que en su momento habría sido reprimida. Por su parte, Cathy Caruth se va a oponer explícitamente a esta interpretación. Desde su perspectiva, "el síntoma traumático no puede ser interpretado, simplemente, como una distorsión de la realidad, (...) ni como la represión de lo que una vez fue deseado (...) sino como el retorno literal del evento contra la voluntad de quien lo vivió (...) Es su literalidad y su insistente retorno lo que constituye el trauma." ${ }^{24}$ El carácter literal que es atribuido al trauma se refiere, en primera instancia, a la reproducción "en sus detalles exactos"25 del evento traumático en cada una de sus repeticiones bajo la forma de alucinaciones, sueños o flashbacks. Pero también aludiría a algo mucho más complejo y polémico: el carácter "no simbólico", "inasimilable a las cadenas asociativas de significado" que tendría el recuerdo traumático. ${ }^{26}$ Su reiteración precisa, su aparente falta de “distorsión” residiría en que dicho recuerdo no entra en las tramas representacionales que habitualmente construyen sentido y permiten la construcción de una historia (tanto en el sentido de story como en el de history). De esa manera, el recuerdo se mantendría "absolutamente fiel (true) al evento". ${ }^{27}$

Al desarrollar su posición, Caruth se detiene a explicar las características o la “estructura"28 de la experiencia traumática, y de los procesos de memoria que se vincularían a ella. Para ello se basa en algunas investigaciones neurobiológicas contemporáneas sobre las particularidades que existirían en la memoria de los sucesos traumáticos. Fundamentalmente, en los trabajos liderados por Bessel van der Kolk que proponen la existencia de dos procesos diferentes de memorización: una "memoria narrativa versus una memoria traumática" ${ }^{29}$ No obstante esta referencia ajena al psicoanálisis, la autora también intenta acercar sus ideas sobre el trauma a las concepciones freudianas, incluyendo varias citas que servirían para justificar que también en Freud aparecería una noción de trauma que no se vincularía ni con los tiempos de la represión y su retorno, ni con las desfiguraciones del recuerdo por el juego representacional. En esa dirección se dirige el comentario de la autora de una extensa cita extraída de uno de los últimos escritos del psicoanalista: el ensayo sobre Moisés. ${ }^{30}$ Llamativamente, la autora no hace ninguna mención al eje central de este texto: la hipótesis de que habría ocurrido un asesinato traumático (el de Moisés y, aún más atrás, el del padre primordial) que habría sido reprimido y del cual habrían persistido marcas en las escrituras sagradas y en algunas particularidades del monoteísmo judío. Más bien, la escritora se detiene en una pequeña referencia de Freud a quienes sufrieron un accidente de ferrocarril y desarrollan síntomas tras un período de latencia. Entonces Caruth afirma:

Pareciera que Freud describe el trauma como el movimiento sucesivo desde el evento a su represión y a su retorno. Sin embargo, lo que es verdaderamente conmocionante en la experiencia de la víctima de un accidente (...), no es tanto el período de olvido que ocurre

\footnotetext{
${ }^{24}$ Cathy Caruth (ed.), Introducción a Trauma: Explorations in memory (Baltimore: The Johns Hopkins University Press, 1995), 5.

${ }^{25}$ Ibid., 153.

${ }^{26}$ Ibid., 5.

${ }^{27}$ Ibid.

${ }^{28}$ Ibid., 4.

${ }^{29}$ Bessel van der Kolk y Onno van der Hart, "The Intrusive Past. The flexibility of Memory and the Engraving of Trauma”, en Cathy Caruth (ed.), Trauma: Explorations in memory, 163.

${ }^{30}$ Sigmund Freud, “Moisés y la religión monoteísta”, en Sigmund Freud, Obras completas, Vol. 23, 1-132.
} 
después del accidente, sino más bien el hecho de que la víctima del choque no estuvo nunca completamente consciente durante el accidente mismo: la persona salió, dice Freud, aparentemente ilesa. La experiencia del trauma, el hecho de la latencia, parece consistir (...) en una latencia inherente e interna a la experiencia misma. ${ }^{31}$

La particular lectura que realiza del "hecho" de la latencia la conduce a ubicar en un texto muy tardío del psicoanalista vienés una división que afecta a la experiencia subjetiva sin desplegarse en una temporalidad cronológica o lógica. La latencia no sería el tiempo segundo que se instalaría tras la represión y que separaría un evento traumático (T1) del momento del retorno sintomático (T3). Más bien, tendría lugar en la experiencia misma: el tiempo primero se escindiría entre un registro literal (Lit) de lo ocurrido y la imposibilidad de acceder a él por la memoria narrativa (Narr), convencional, consciente (T1: Lit / Narr). Luego, esa misma escisión se repetiría cada vez que la reiteración literal del T1 produciría un nuevo fracaso de su expresión narrativa. Para Caruth, la última apreciación freudiana sobre el trauma sugeriría que "lo que el trauma tiene que decirnos - la verdad histórica y personal que transmite - está intrínsecamente enlazada al rechazo de los lazos históricos; que su verdad está ligada con una crisis de verdad. ${ }^{\text {„2 }}$ Curiosamente, no aparecen referencias a la perspectiva económica sobre el trauma, acentuada en los últimos años de la obra del psicoanalista, sino a una latencia o retardo (belatedness) ${ }^{33}$ que, entendido como división interna a la experiencia, abarcaría la totalidad de la obra freudiana. ${ }^{34}$

Quisiéramos señalar algunos problemas de esta conceptualización. Si se trata de señalar, como parece, un punto de discontinuidad en una trama narrativa, ¿por qué llamarlo "literal" si se trata, justamente, de algo que no parece terminar de inscribirse? Seguramente, dicho término refuerza la idea de un registro exacto de lo ocurrido. Pero justamente por eso podría conducir a un malentendido problemático. Si el sueño, la alucinación o el flashback vivido por una persona reproduciría precisa y exactamente un acontecimiento de violación, tortura, etc., entonces podría creerse que se tendría la garantía de que el acontecimiento repetido en esos fenómenos ocurrió exactamente en la misma forma en la que se presenta en la reiteración. Los síntomas de la repetición devendrían entonces una copia exacta del suceso y convertirían al traumatizado en un testigo perfecto (negando de este modo las dificultades y los problemas vinculados al testimonio en primera persona de los acontecimientos traumáticos).

Por otro lado, la concepción del trauma como una experiencia de la que queda un registro exacto, pero "escindido" de la memoria consciente, parece acercarse más al texto que Freud escribió con Josef Breuer en $1893^{35}$ que a los últimos artículos del psicoanalista. En ese artículo, los autores afirman que "los recuerdos que han devenido ocasionamiento de fenómenos histéricos se han conservado por largo tiempo con asombrosa frescura y con su plena afectividad"; pero, al mismo tiempo, "los enfermos no disponen de estos recuerdos como disponen del resto de su vida. Al contrario, estas vivencias están completamente

\footnotetext{
${ }^{31}$ Cathy Caruth, Introducción a Trauma, 7-8.

${ }^{32}$ Ibid., 8.

${ }^{33}$ Ibid.

${ }^{34}$ Ibid., 9.

35 Josef Breuer y Sigmund Freud, “Sobre el mecanismo psíquico de fenómenos histéricos: comunicación preliminar”, en Sigmund Freud, Obras completas, Vol. 2, 27-44.
} 
ausentes de la memoria de los enfermos en su estado psíquico habitual.”36 Como reconocen los mismos médicos vieneses, como también la propia Caruth, esta doctrina, que supone una escisión entre la memoria habitual y el registro del trauma, ya se hallaba presente en Janet. Pero también, de manera incipiente, en ciertos pasajes de Charcot, quien podía reconocer que una idea que implicara una acción, si era introducida en un estado de alteración de la conciencia, podría conducir a quien la portaba a repetirla sin modificaciones y sin que la conciencia pudiera ni ubicar su origen ni contradecirla. Como se puede apreciar, el modelo del que parte una concepción así de la memoria y del trauma no es otro que el de la hipnosis. Y, entonces, por paradójico que resulte, las ideas que sostiene Caruth sobre un registro literal, exacto, verdadero del trauma tiene su origen en la técnica que más resalta la dimensión sugestiva y engañosa de la experiencia y la memoria.

Por último, es necesario resaltar que la perspectiva adoptada por esta autora conduce a la imposibilidad de historizar el trauma (al menos en las formas que sostiene la historiografía tradicional). Pues, por un lado, no sería posible establecer la distancia necesaria entre el testigo y quien escucha, entre el problema a investigar y el sujeto que pretende conocerlo. Según Caruth, "escuchar lo imposible” no es una elección sino que es necesario "haber sido elegido por ello, antes de existir la posibilidad de dominarlo a través del conocimiento. Ese es el peligro (...) del contagio del trauma, de la traumatización de quien escucha. Pero también es la única posibilidad para su transmisión.”37 Por otro lado, porque no sería posible narrar el trauma sin que éste desaparezca, sin que deje de ser lo que esencialmente es. "La transformación del trauma en una memoria narrativa que permite que la historia sea verbalizada y comunicada, sea integrada en nuestro propio conocimiento del pasado y en el de otros, puede hacer perder tanto la precisión como la fuerza que caracteriza a la evocación traumática." ${ }^{38}$ Es cierto que algo equivalente podría decirse de la relación entre historia y política: la primera parece enfriar las pasiones de la segunda, pues precisa hacer de sus objetos de indagación un pasado muerto que no llega a (y se distingue del) presente. Pero, un cierto aire de sacralización del trauma parece desprenderse del espíritu del texto de Caruth. Al citar a van der Kolk y van der Hart, la autora se pregunta si la posibilidad de integración del trauma en la memoria y la historia no sería "un sacrilegio de la experiencia traumática”. ${ }^{39}$

\section{Freud y la temporalidad nachträglich}

Consideramos preciso comenzar a analizar la primera de las temporalidades delineadas por Freud en relación al trauma que, como anticipábamos, no coincide simplemente con el retorno de lo reprimido. La primera versión extendida de esta concepción temporal fue presentada en 1896, junto con una serie de hipótesis sobre la etiología de las neurosis conocida como "teoría de la seducción”. Pero para entender estos planteamientos es necesario retrotraerse a un par de años antes, cuando el psicoanalista vienés introdujo sus primeras ideas sobre la represión.

\footnotetext{
${ }^{36}$ Ibid., 35.

${ }^{37}$ Cathy Caruth, Introducción a Trauma, 10.

${ }^{38}$ Ibid., 153.

${ }^{39}$ Ibid., 154.
} 
En 1894, Freud escribió un pequeño artículo donde procuró fundamentar que la escisión que separa el recuerdo del trauma de las representaciones que forman parte de la conciencia no sería un dato primero (como afirmaba Janet), sino más bien la consecuencia de un acto por el cual la persona intenta defenderse de una representación inconciliable con el resto de las representaciones del yo. ${ }^{40} \mathrm{Al}$ presentarse dicha representación frente al yo, se establece un "conflicto" que conduce a la persona "a olvidarla, no confiando en poder solucionar con su yo, mediante un trabajo de pensamiento, la contradicción que esa representación inconciliable le oponía." ${ }^{41}$ En ese marco, no es la naturaleza o el contenido intrínseco de la representación sino su "relación inconciliable" y conflictiva con el yo la que la convierte en traumática, pues conduce a la represión de la representación (que, desde entonces, permanecerá inconsciente y separada del yo), y al desplazamiento del afecto (que conducirá a la formación de los síntomas como un modo desfigurado de retorno de lo reprimido).

Cuando en 1896 retome sus ideas sobre las neuropsicosis de defensa para profundizar sobre la cuestión etiológica, Freud mantendrá buena parte de este esquema. El comienzo de la patología no se ubicaría en el momento de aparición de los síntomas sino antes, cuando en la madurez se produce un conflicto (T1) que conduce a la represión (R) de una representación inconciliable. A partir de entonces se iniciaría el período de "salud aparente" ${ }^{42}$ o latencia (T2), cuya finalización coincide con la aparición de los síntomas, es decir, con el retorno desfigurado de lo reprimido (T3).

Hasta aquí el esquema conceptual parece reproducir la misma secuencia planteada por LaCapra. El único matiz diferencial que podría señalarse es que lo que retorna del tiempo 1 no puede hacerlo inmodificado: los síntomas son "unas formaciones de compromiso entre las representaciones reprimidas y las represoras". ${ }^{43}$ Lo que irrumpe en el tiempo 3 se encuentra determinado tanto por el pasado reprimido como por la organización presente de las representaciones conscientes.

No obstante, si la explicación se detuviera aquí, Freud seguiría dejando inconcluso un problema que ya había sido esbozado en 1894: ¿por qué hay "personas que permanecen sanas ante las mismas influencias psíquicas”, ${ }^{44}$ mientras que otras no confían "en poder solucionar con su yo, mediante un trabajo de pensamiento, la contradicción que esa representación inconciliable le imponía” ${ }^{45}$ y, por ende, caen en la represión y la neurosis?

En otras palabras, en la perspectiva freudiana un conflicto no necesariamente sería traumático ni conduciría en todos los casos a la represión de lo inconciliable. Por esta razón

\footnotetext{
${ }^{40}$ Sigmund Freud, "Las neuropsicosis de defensa (Ensayo de una teoría psicológica de la histeria adquirida, de muchas fobias y representaciones obsesivas, y de ciertas psicosis alucinatorias)”, en Sigmund Freud, Obras completas, Vol. 3, 41-68.

${ }^{41}$ Ibid., 49.

${ }^{42}$ Sigmund Freud, "Nuevas puntualizaciones sobre las neuropsicosis de defensa", en Obras completas, Vol.

3, 170 .

${ }^{43}$ Ibid.

${ }^{44}$ Sigmund Freud, “Las neuropsicosis de defensa”, 50.

${ }^{45}$ Ibid., 44.
} 
el campo del trauma se ve sensiblemente acotado y, al mismo tiempo, se vuelve preciso considerar una predisposición particular para que la emergencia de un conflicto obtenga una resolución patológica. Hasta ese entonces, la herencia ocupaba el lugar de dicha predisposición. Y ese es el punto que Freud se propuso discutir en 1896 al introducir una nueva concepción de la temporalidad y del trauma que supone relaciones complejas entre el pasado y el presente. En palabras de Freud, el peso predisponente otorgado a la herencia "puede remplazarse enteramente o en parte por el efecto póstumo (posthume) del trauma infantil sexual. Sólo consiguen 'reprimir' el recuerdo de una vivencia sexual penosa de la edad madura aquellas personas en quienes esa vivencia es capaz de poner en vigor la huella mnémica de un trauma infantil.,"46

Así sólo devendrán neuróticos aquellas personas que vivieron en su infancia una seducción y, en la adultez, se enfrentaron a una representación que "puede entrar en un nexo lógico o asociativo con una de tales vivencias infantiles." " Para que alguien enferme, se precisa un tiempo anterior (T0), el de la marca de la predisposición, que es el que genera las condiciones para que se establezca la serie de los momentos de la enfermedad. Ese punto cero es el que Freud considera la causa específica de la patología.

(T0)

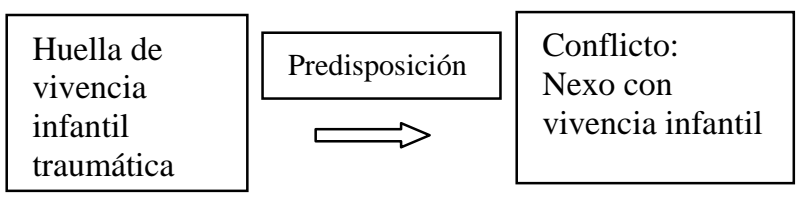

(R)

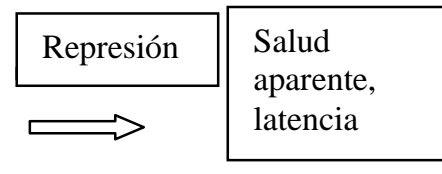

(T3)

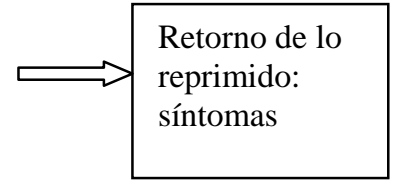

Ahora bien, si dejáramos las cosas en este punto, nos encontraríamos con un esquema prospectivo, que parecería indicar una relación causal, lineal y unidireccional entre el abuso infantil pretérito y la enfermedad presente. Si así fuera, al esquema de LaCapra sólo se le hubiese agregado un tiempo anterior, sin modificar la idea de que la temporalidad del trauma encuentra su rasgo esencial en el retorno de un pasado reprimido, cuyas experiencias determinarían el presente sintomático. Empero, es posible hallar en el texto freudiano una serie de indicaciones que cuestionan el peso intrínseco de las vivencias pasadas y complejizan la temporalidad del trauma. En principio, las vivencias infantiles quedarían relativizadas por la afirmación de que éstas tuvieron en su momento un "efecto nulo o escaso", ${ }^{48}$ y "sólo podrían exteriorizar un efecto psíquico a través de sus huellas mnémicas". ${ }^{49}$ Es necesario aquí comenzar a hacer una distinción entre acontecimiento y huella. El valor de los primeros parecería residir en la "marca" que inscriben en el psiquismo. La experiencia en sí queda perdida; pero de ella habrá de conservarse una “inscripción” que actúa como punto de fijación y que es lo que va a permitir el ordenamiento de los puntos posteriores.

\footnotetext{
${ }^{46}$ Sigmund Freud, "Nuevas puntualizaciones”, 167.

${ }^{47}$ Sigmund Freud, “La etiología de la histeria”, en Sigmund Freud, Obras completas, Vol. 3, 209.

${ }^{48}$ Sigmund Freud, "La herencia y la etiología de las neurosis”, en Sigmund Freud, Obras completas, Vol. 3, 153.

${ }^{49}$ Sigmund Freud, “La etiología de la histeria”, 201.
} 
Por ende, "no son las vivencias mismas las traumáticas, sino su reanimación posterior como recuerdo". ${ }^{50}$ Esta frase aparentemente simple, supone una complejidad que queremos explicitar. Ya hemos matizado el valor del acontecimiento; ahora es necesario sopesar la importancia de la huella. Ésta tampoco puede ser traumática por su mera presencia: sólo vale como la marca de una predisposición. Para que "devenga" trauma, debe ser despertada en un tiempo posterior: el del conflicto presente. Sólo se constituye el trauma cuando el conflicto reanima la huella y hace de ésta un recuerdo presente, un pasado actual.

(T0)

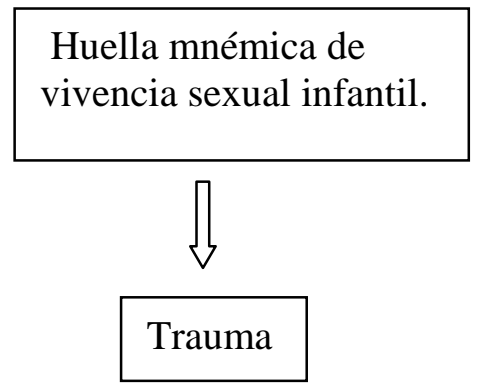

(T1)

Conflicto : nexo con vivencia infantil

Esta dirección "retroactiva” fue subrayada por muchos psicoanalistas, especialmente de orientación lacaniana. Como sugiere Omar Acha, la Nachträglichkeit freudiana ha sido habitualmente traducida, leída e interpretada "bajo la figura temporal del après coup". 51 Este sesgo en la interpretación del término freudiano corre el riesgo de ocultar el peso predisponente que para Freud tenían las huellas de la infancia respecto del desarrollo futuro. Efectivamente, hay en el texto del psicoanalista vienés una dirección "prospectiva". Pero predisposición no es necesidad; sólo genera las condiciones de posibilidad de la enfermedad. Para que ésta surja se precisa, además, el advenimiento de un conflicto actual que se asocie con esa marca pretérita. Únicamente si se asocian esos dos elementos se vuelve posible "otra comprensión de lo recordado". ${ }^{2}$ Sólo desde ese presente conflictivo, el pasado se convierte en trauma y, entonces, despierta la represión y posibilita las condiciones para que las experiencias pretéritas retornen como síntoma o repetición, en lugar de hacerlo como recuerdo.

Hay otro punto importante que quisiéramos incluir en nuestro análisis. En todos los textos de 1896, se afirma que por el despertar del recuerdo de la vivencia infantil, la "huella no deviene entonces consciente, sino que conduce al desprendimiento de afecto y a la represión". ${ }^{53}$ Esta frase introduce la posibilidad de considerar una memoria que se mida por sus efectos aún cuando no traiga un recuerdo a la conciencia. ${ }^{54}$ Es decir, una memoria que no se limitaría a la rememoración: ésta puede faltar, pero aun así el recuerdo opera, posibilitando otro modo (inconsciente) de recordar.

\footnotetext{
${ }^{50}$ Sigmund Freud, “Nuevas puntualizaciones”, 165.

${ }^{51}$ Omar Acha, “No todo es historia. Lacan y los entretiempos freudianos”, en Inconciente e historia después de Freud, 271.

52 Sigmund Freud, "Proyecto de psicología para neurólogos”, en Obras completas, Vol. 1, 403.

53 Sigmund Freud, “Nuevas puntualizaciones”, 167.

${ }^{54}$ Esta concepción psíquica de la memoria se basa en el modelo de una memoria fisiológica y biológica, corriente en el evolucionismo de fines del siglo XIX.
} 
En síntesis, la temporalidad nachträglich introduciría en el terreno del trauma y de la memoria una relación no lineal entre pasado y presente. Lo que ha sido dejaría marcas que condicionarían al presente. El valor de la experiencia actual dependería, en parte, de su conexión con las huellas pretéritas. Pero el pasado no determinaría plenamente al presente, ni siquiera en el caso del retorno de lo reprimido vía el síntoma o la repetición. Más aún, cada presente otorgaría al pasado un valor nuevo, pudiendo incluso hacer devenir traumática una experiencia que, en su momento, no lo fue. Al mismo tiempo, si la memoria vinculada a esta temporalidad supone una eficacia y una persistencia del pasado independiente de su registro consciente, llegar a recordar implicaría modificar la relación conflictiva del presente con el pasado, es decir, elaborar las resistencias al recuerdo.

Pero esta concepción delineada en 1896 fue, en parte, abandonada un año después, cuando Freud comenzó a concebir la posibilidad de que el relato de las escenas de seducción pudiera no ser más que una fantasía. O, para ser más preciso, que la memoria narrada sobre hechos conflictivos y muy alejados del presente puede contener unas desfiguraciones tales que no permiten garantizar la coincidencia entre la escena relatada y la escena vivida. ${ }^{55}$

No obstante, lo que se mantuvo vigente a lo largo de toda su obra es la concepción de memoria y de temporalidad que acabamos de describir. Por ejemplo, Freud utilizó este modelo en el análisis de la historia del pueblo judío y el monoteísmo. Las divergencias y contradicciones presentes en la escritura bíblica son analizadas por el autor como formaciones de compromiso que darían cuenta del retorno de un pasado reprimido: el de un supuesto asesinato del líder Moisés (T1) que, en el momento de la realización de un pacto fundacional entre distintas tribus, resultaba demasiado conflictivo como para ser incluido en la memoria (R). Este acontecimiento se vincularía con (y reavivaría a) el asesinato de un "padre primordial", que habría reinado irrestrictamente en las hordas pre-humanas hasta que sus hijos lograron matarlo. Con esta ficción inspirada en Darwin (y que Freud suponía acontecimiento vivido), se intentaba explicar el origen de la cultura y la inscripción de una marca primera (T0) que se transmitiría, reeditaría y resignificaría a lo largo de las generaciones. De esta manera, los destinos atribuidos a Moisés y a Cristo darían cuenta, en la historia de la cultura occidental, de la repetición de un trauma primero y de su permanente resignificación; de la fuerza del pasado sobre el presente y del modo en que éste último transforma las huellas primeras.

Por otro lado, este esquema temporal es el que, grosso modo, suele aparecer en el terreno de la historiografía reciente, cuando se apela a alguna noción de trauma inspirada en el psicoanálisis para dar cuenta de la incidencia en el terreno de la memoria de un pasado considerado traumático. Por ejemplo, en el ya clásico estudio de Henry Rousso sobre el período de Vichy, ${ }^{56}$ no se menciona explícitamente la noción de trauma, pero se apela permanentemente a una temporalidad centrada en los efectos retardados que las

\footnotetext{
${ }^{55}$ A pesar de lo dicho, para Freud toda fantasía tiene su fundamento y su origen en un hecho acontecido (al que desfigura), sea en la vida de la persona, sea en la vida de los antepasados, incluso los más remotos (y, en ese caso, transmitido filogenéticamente).

${ }^{56}$ Henry Rousso, Le syndrome de Vichy. De 1944 á nos jours (Paris: Seuil, 1990).
} 
experiencias de la Segunda Guerra habrían tenido sobre la memoria colectiva francesa. Según este autor, tras unos tibios e inacabados intentos de revisar y procesar lo ocurrido en la sociedad francesa durante el conflicto bélico, habría sobrevenido una represión, dado que Vichy resultaba un pasado demasiado conflictivo respecto de la imagen de una nación "resistente" a la ocupación, representación que tanto los partidarios de De Gaulle como los comunistas querían imponer. Luego de una latencia, una serie de hechos nimios (entre los que ocuparía un lugar importante la proyección del filme Le Chagrin et la Pitié que revisita la vida cotidiana durante la ocupación) habrían reavivado la huella de un pasado reprimido: el de las complicidades y las aceptaciones pasivas al régimen nazi. Desde entonces, ese pasado resignificado no habría cesado de retornar hasta convertirse en obsesión.

Daniel Lvovich presenta un panorama similar en lo que respecta al pasado fascista en la Italia de posguerra. ${ }^{57}$ Así, hasta la década de los sesenta el interés historiográfico por el fascismo era escaso, en la misma medida en que se consideraba a su régimen como una anomalía, una enfermedad de unos pocos que habrían “ocupado” la nación. Pero, tras la publicación de una obra de Renzo De Felice, “quien defendió la noción de que existió un marcado consenso en torno al fascismo (...), se pudo romper el tabú que impedía el estudio del fascismo". ${ }^{58}$

Para algunos historiadores, este esquema sostenido en la temporalidad nachträglich, la represión y el retorno de lo reprimido no podría aplicarse a la última dictadura militar argentina porque no se habría producido una latencia en la memoria sobre la experiencia dictatorial. ${ }^{59}$ Sin embargo, esta apreciación es cuestionable pues, si bien no puede hablarse de una brecha tan prolongada como en los casos europeos mencionados, sí sería posible ubicar un período de silencio entre las primeras apariciones de los sobrevivientes de los campos y el fin de la Guerra de Malvinas, momento en el que los medios de difusión de masas empiezan a difundir el horror de los campos de una dictadura entonces desfalleciente. Podría creerse que dicho silencio era impuesto por el ejercicio del terror dictatorial y el temor a una represalia "desde arriba". Sin embargo, como señala Hugo Vezzetti, la dificultad para formular y alojar el testimonio aparecía también en la posición de familiares y allegados de los sobrevivientes que "no querían saber" de las torturas y demás vejaciones que ocurrían, muchas veces, a la vuelta de la esquina. ${ }^{60}$ Fue necesario que una guerra inútil mostrara a los jóvenes soldados como víctimas de un régimen desquiciado, para que otras víctimas, aquéllas de los campos, pudieran ser visibilizadas y escuchadas. Si las representaciones sociales que planteaban la existencia de una guerra (revolucionaria o antisubversiva) impedían ver el horror de las desapariciones y el exterminio, el conflicto bélico del Atlántico Sur y el posterior Juicio a la Junta Militar reordenó las representaciones presentes y resignificó, a posteriori, la experiencia vivida (y reprimida) de la dictadura militar.

\footnotetext{
${ }^{57}$ Daniel Lvovich, "Historia reciente de pasados traumáticos. De los fascismos y colaboracionismos europeos a la historia de la última dictadura argentina”, en Florencia Levín y Marina Franco, Historia reciente. Perspectivas y desafíos para un campo en construcción (Buenos Aires: Paidós, 2007).

${ }^{58}$ Ibid.,106.

${ }^{59}$ Enzo Traverso, "Historia y memoria. Notas sobre un debate”, en Florencia Levín y Marina Franco, Historia reciente, 84. Daniel Lvovich, "Historia reciente de pasados traumáticos”, 98 y 116.

${ }^{60}$ Hugo Vezzetti, Pasado y presente. Guerra, dictadura y sociedad en al Argentina (Buenos Aires: Siglo XXI, 2002), 181.
} 
Además, si tomamos en consideración las tesis de Freud respecto de la necesidad de un tiempo anterior, predisponente, para que un conflicto devenga trauma, el modelo freudiano obligaría a concentrar la atención en los momentos previos a la experiencia considerada traumática, para poder, a su vez, arrojar luz sobre sus condiciones de posibilidad $^{61}$.

A continuación, analizaremos otra conceptualización del trauma presente en la obra de Freud.

\section{Freud y la perspectiva económica del trauma}

En la medida en que la Primera Guerra Mundial volvía a poner sobre el tapete los problemas en torno a las entonces llamadas "neurosis traumáticas", un viraje importante se iba a producir en la concepción freudiana del trauma. A partir de entonces, el eje no iba a estar en el conflicto entre representaciones o escenas inconciliables, sino en los límites de una escena, a partir de la consideración de un afecto cuya magnitud resulta imposible de ser ligada a una trama representacional.

Quisiéramos comenzar nuestra exposición con la siguiente cita:

(Las neurosis traumáticas) nos enseñan el camino hacia una concepción, llamémosle económica, de los procesos anímicos. Más aún: la expresión 'traumática’ no tiene otro sentido que ese, el económico. La aplicamos a una vivencia que en un breve lapso provoca en la vída anímica un exceso tal en la intensidad de estímulo que su tramitación o finiquitación por vías habituales y normales fracasa, de donde por fuerza resultan trastornos duraderos para la economía energética. ${ }^{62}$

Consideramos importante subrayar algunos elementos de este fragmento. En términos económicos, el trauma aparece ligado a un exceso, a una presencia que se introduce en un "breve lapso" temporal y supera los límites de un aparato anímico. Por eso mismo, no depende únicamente de la naturaleza de la vivencia sino de la relación entre lo que ésta puede generar y la capacidad de tramitación de un psiquismo en particular. Por último, el efecto del trauma se verifica en la vivencia misma (el fracaso de su tramitación) y también en la persistencia del trastorno que genera (por ejemplo, bajo la forma de una compulsión a la repetición).

\footnotetext{
${ }^{61}$ Movimiento que viene ocurriendo en los últimos años en la Argentina, con la consecuente multiplicación de trabajos memorísticos e históricos sobre el período del gobierno constitucional anterior al golpe de Estado (1973-1976).

${ }^{62}$ Sigmund Freud, “18 Conferencia de introducción al psicoanálisis. La fijación al trauma, lo inconciente”, en Sigmund Freud, Obras completas, Vol. 16, 251-252.
} 
En el decenio posterior, tras la finalización del conflicto bélico, se profundiza la perspectiva económica en la consideración del trauma. Hasta entonces, Freud sostenía que el aparato psíquico se hallaba regido por el principio del placer, es decir, por el intento de evitar el displacer que se generaría por el incremento de tensión en el interior del sistema. En el texto "Más allá del principio del placer" el autor se detiene en una serie (algo heterogénea) de experiencias que parecen contradecir dicha tendencia, pues todas se caracterizarían por una repetición que se impone a pesar de generar displacer. Entre tales experiencias se encontrarían las propias de las neurosis traumáticas, cuyo tinte afectivo común es el "terror", es decir, un afecto no placentero intenso que se caracteriza por la ausencia de la preparación. Lo que queda subrayado es el "factor de la sorpresa", 63 como si el evento situara algún orden de discontinuidad respecto de lo que podía preverse de acuerdo con el espacio de la experiencia previa. Al mismo tiempo, Freud se detiene en un rasgo de la vida onírica propia de estos cuadros: los sueños "reconducen al enfermo una y otra vez a la situación de su accidente, de la cual se despierta con renovado terror”. ${ }^{64}$ Podría creerse que de estas líneas pueden desprenderse algunas de las ideas sostenida por Caruth. Sin embargo, es preciso señalar que para Freud lo repetido no recaería en los detalles de la escena sino en una nueva producción del terror. El acento freudiano sobre la repetición parecería posarse menos en la literalidad y exactitud y más en la naturaleza vívida del afecto presente.

Para explicar en términos económicos dicha experiencia, el psicoanalista se introduce en un terreno que él mismo califica de especulativo. ${ }^{65} \mathrm{Su}$ argumentación se sostiene en una construcción sobre el funcionamiento de los organismos unicelulares respecto del tratamiento de las cantidades de estímulo provenientes del mundo exterior. Con tal ficción, espera poder explicar en términos económicos las situaciones traumáticas, así como también toda la serie de experiencias que implican una compulsión a la repetición.

De acuerdo con esta metáfora, en un ser vivo simple - como también en el aparato psíquico - existiría una barrera de "protección antiestímulo" que operaría "apartando los estímulos" hipertróficos que podrían poner en cuestión el funcionamiento económico del sistema y generar un displacer enorme. ${ }^{66}$ A partir de esta ficción, podría definirse como "traumáticas a las excitaciones externas que poseen fuerza suficiente para perforar la protección antiestímulo (...). Un suceso como el trauma externo provocará (...) una perturbación enorme en la economía energética del organismo"; entonces, el aparato anímico parece verse "anegado por grandes volúmenes de estímulo”. ${ }^{67}$ En estas líneas, la situación traumática empieza a quedar definida en relación a un "agujero" (en las fronteras que circunscriben el interior del sistema) y a una "presencia" de un elemento heterogéneo (las cantidades hipertróficas ajenas al funcionamiento habitual de aquél).

A partir de este punto Freud se apoya en una diferenciación establecida por Breuer entre "energía de investidura quiescente (ligada)", ${ }^{8}$ que sería la propia de "los sistemas

\footnotetext{
${ }^{63}$ Sigmund Freud, “Más allá del principio del placer”, en Sigmund Freud, Obras completas, Vol. 18, 13.

${ }^{64}$ Ibid.

${ }^{65}$ Ibid., 24.

${ }^{66}$ Ibid., 27.

${ }^{67}$ Ibid., 29.

${ }^{68}$ Ibid., 26.
} 
psíquicos”, 69 y otra "libremente móvil”, que sería aquélla que se presenta en el exterior del aparato anímico. ${ }^{70}$ A partir de esta nueva distinción, Freud define la exigencia que la situación traumática le impondría al psiquismo: “dominar el estímulo, ligar psíquicamente los volúmenes de estímulo que penetraron violentamente a fin de conducirlos, después, a su tramitación.” Si el aparato psíquico es concebido como una trama de representaciones y energía ligada, que pretende regirse por el principio del placer, el trauma se presentaría como un momento de discontinuidad en ese funcionamiento. Por eso obligaría al sistema a una tarea previa destinada a la evitación del displacer: la "ligazón de la energía que afluye al aparato anímico". ${ }^{71}$

En parte, la compulsión a repetir el trauma podría explicarse a partir de este intento de ligadura del elemento heterogéneo al sistema. Por ejemplo, si el terror que emerge en la situación traumática describe el tenor afectivo propio de una falta de preparación para la llegada de estímulos al aparato, los sueños repetitivos de las neurosis traumáticas buscarían "recuperar el dominio sobre el estímulo por medio de un desarrollo de angustia”, de un "apronte angustiado, con su sobreinvestidura de los sistemas recipientes". ${ }^{72}$ Sin embargo, la referencia (citada más arriba) a un despertar con "renovado terror”, daría cuenta del fracaso de la tarea. El proceso se desarrollaría de un modo tal que la trama tejida por la actividad onírica conduciría, otra vez, al encuentro con un agujero que no termina de ser recubierto y con un exceso que no termina de ser perdido. En ese instante de discontinuidad se produciría el despertar, para luego dar paso a las tramas representacionales propias de la vigilia. ${ }^{73}$ Por otro lado, de acuerdo con esta perspectiva no sería la escena primera en su totalidad la que resultaría traumática, sino la irrupción en su marco de un elemento que despierta el terror. ${ }^{74}$

Algo análogo ocurriría con "los sueños que se presentan en los psicoanálisis, y que nos devuelven el recuerdo de los traumas psíquicos de la infancia”. ${ }^{75}$ En relación a ellos, Freud da una indicación que consideramos de importancia para situar algunas características de la memoria en relación al trauma. Esos sueños obedecerían a "la compulsión a la repetición, que en el análisis se apoya en el deseo (promovido ciertamente por la sugestión) de convocar lo olvidado y reprimido" ${ }^{76}$ El tratamiento analítico intenta procurar el recuerdo del pasado caído en la represión. Pero, al seguir las huellas que conducen hacia él, la memoria se topa con un agujero donde emerge, nuevamente, un factor cuantitativo que intentaría ser ligado vía la repetición en el sueño o vía la acción desplegada en la transferencia con el analista.

\footnotetext{
${ }^{69}$ Ibid., 30.

${ }^{70}$ Ibid., 26.

${ }^{71}$ Ibid., 30-31.

${ }^{72}$ Ibid., 31.

${ }^{73}$ Esta caracterización del despertar, que se adecua muy bien al fenómeno descripto por Freud, fue planteada por Lacan en sus Seminarios XI y XIV.

${ }^{74}$ Por ejemplo, la escena en la trinchera, el diálogo con los compañeros, las quejas por el cansancio y las heridas, pueden ser tristes, dolorosas o atemorizantes. Pero se despliegan (en la experiencia misma y en su recuerdo) en una continuidad que sólo es interrumpida por la irrupción inesperada de una bomba, por la inclusión inconcebible de la tortura, etc.

${ }^{75}$ Sigmund Freud, “Más allá del principio del placer”, 32.

${ }^{76}$ Ibid.
} 
Por otro lado, el que la repetición insista más allá del fracaso de la función vinculadora y de la emergencia del displacer es lo que conduce a Freud a reconocer en ella otra dimensión: algo (pulsional) empujaría a obtener la misma paradójica satisfacción producida por el exceso que se presentó una vez, y hacerlo por los mismos caminos que delineó entonces, aun cuando estas vías conduzcan al displacer e, incluso, a la muerte.

Quisiéramos recapitular lo expuesto hasta aquí. La situación traumática reuniría en sí la conjunción entre la ruptura en una trama representacional y la presencia de un elemento cuantitativo que parece imposible ser ligado a dicha trama (Agujero/Presencia). Sin embargo, la imposibilidad que se establece en ese instante discontinuo no es de naturaleza sino relacional: depende de la articulación que se establezca entre la magnitud de estímulo y el grado de preparación del sistema para acogerlo, entre el elemento no-ligado y el modo en que se ligan los elementos del sistema. Luego, la repetición de la experiencia en un tiempo posterior, se produciría cuando la deriva por una trama representacional acerca al sujeto al mismo punto de ruptura (por ejemplo, cuando se lo invita a recordar la experiencia traumática), por donde se introduce nuevamente un exceso. A su vez, dicha repetición estaría motivada por el intento de ligadura y por la compulsión a recorrer los mismos trazos dejados en el pasado por la excitación.

Por su carácter relacional, esta concepción se diferencia de la de Caruth que describimos más arriba. Según esta autora, en la ocurrencia del trauma, la experiencia quedaría escindida entre un registro literal y una memoria narrativa, lo cual supone dos procesos memorísticos de naturaleza distinta. En cambio, para Freud el psiquismo no excluye a los afectos como un elemento esencialmente heterogéneo, aunque se encuentren límites a la posibilidad de ligarlos. En la práctica, esta concepción no conduciría a una sacralización del trauma en tanto poseedor de una verdad ni a la imposibilidad de memorizar o historizar las experiencias traumáticas (lo cual, por el contrario, constituye una de las metas de un psicoanálisis). Pero sí abriría la posibilidad de que una modificación de la organización de los elementos ligados posibilitara también una "inscripción” o ligadura del exceso cuantitativo que se repite desde la situación traumática (lo cual supondría la “pérdida” del carácter vivido, presente del afecto).

Esta perspectiva económica también se distancia de la consideración del trauma a partir de una pérdida. Cuando en 1926, Freud se detiene en un análisis pormenorizado de la angustia, la primera impresión es que ésta sería la reacción frente a una pérdida (de la madre, del pene, del amor de los padres, etc.). Cuando ésta sucede, o simplemente amenaza, la angustia funcionaría como una señal para poner en marcha los mecanismos de defensa, dado el peligro que esas pérdidas conllevarían para el psiquismo. Pero, ¿en qué consiste el peligro? Al abordar este interrogante, Freud se introduce nuevamente en una perspectiva económica y la cuestión de la pérdida queda subordinada a ella.

Cuando el niño añora la percepción de la madre, es sólo porque ya sabe, por experiencia, que ella satisface sus necesidades sin dilación. Entonces, la situación que valora como peligro y de la cual quiere resguardarse es la de la insatisfacción, (...) la perturbación económica por el incremento de las magnitudes de estímulo en espera de tramitación; este factor constituye, pues, el núcleo genuino del peligro. ${ }^{77}$

${ }^{77}$ Sigmund Freud, “Inhibición, síntoma y angustia”, en Obras completas, Vol. 20, 130. 
Esta perturbación económica, en general, no llega a ocurrir. Habitualmente se limita a ser una expectativa, pues la angustia señala la inminencia del peligro y llama a los mecanismos defensivos que permiten evitar nuestro desvalimiento frente a las cantidades de excitación. Por eso una pérdida no suele constituirse como trauma: existen modos de responder a ella que evitan el grado de malestar, parálisis, discontinuidad propio del trauma. La angustia es uno de ellos; el duelo, otro. No obstante, cuando el desvalimiento deja de ser una expectativa y se convierte en experiencia vivida nos encontramos con una situación traumática en sentido estricto. ${ }^{78}$

Si, desde esta perspectiva el trauma no sería equivalente a una pérdida sino a la presencia de un afecto que no termina de perderse ni de ligarse a las representaciones con las que habitamos el mundo, las ideas de Freud se alejan de las de LaCapra y de las de muchos otros autores que reflexionaron sobre el trauma en la historia. Para las pérdidas históricas bien vale el modelo del duelo como trabajo (colectivo y social) que apunte a la aceptación de aquellas. Pero, de esta manera, permanecería sin esclarecer lo que distinguiría una pérdida de un trauma; o, a la inversa, se entendería toda pérdida como traumática. En cambio, la conceptualización freudiana como una irrupción inasimilable, como un exceso que no termina de perderse, como una presencia en el lugar de un agujero en una trama representacional y memorística, pone en cuestión la idea de superación de los traumas históricos a partir del trabajo del duelo.

Más bien, paradójicamente, la superación del trauma se acercaría a la escritura de la historia, tal como fue planteada ésta por Michel De Certeau: la inscripción en el presente de un pasado considerado, en adelante, como muerto. ${ }^{79}$ Sólo entonces, después de una operación que hace perder el carácter vívido del resto pretérito, tendría sentido plantear la necesidad de aceptación de la pérdida de aquello que ya no puede ser recuperado del pasado.

Por último, quisiéramos plantear algunas preguntas sobre la pertinencia de este modelo para algunos casos históricos. Por ejemplo, la figura del desaparecido, con su inherente falta de inscripción, ¿no constituye una presencia traumática en el lugar de un agujero en la continuidad de una historia? Los campos de concentración, ¿no ocuparían un lugar de exterioridad y de excepción respecto de una trama de representaciones colectivas que supone la organización de la sociedad civil y el estado a partir de la ley? No es este el momento en que quisiéramos abordar estos interrogantes. Tan sólo quisiéramos plantear que la consideración de esta perspectiva económica del trauma tal vez pueda servir para evitar algunos problemas comunes en los usos habituales de la categoría en el terreno del pasado reciente. Por ejemplo, el de calificar globalmente de traumática a la totalidad de un proceso histórico (como ocurre con la última dictadura argentina) en lugar de circunscribir lo traumático a algunos elementos del mismo, o el de suponer la necesidad de un proceso de duelo, de elaboración o de reconciliación cuando ni siquiera han terminado de inscribirse (de manera simbólica, judicial e historiográfica) las heridas de ciertos pasados que aún permanecen vivos.

\footnotetext{
${ }^{78}$ Ibid.,155.

${ }^{79}$ Michel de Certeau, La escritura de la historia (México: Universidad Iberoamericana, 1999).
} 


\section{Profile}

The author is enjoying a scholarship from the UBACyT program of the University of Buenos Aires (Argentina), where is currently researching for his $\mathrm{PhD}$ on the history of the notion of trauma and its uses in historiography. He also lectures in the history of Psychology. Author of numerous articles on the history of psychoanalysis, historiography and history of the recent past, he is besides a psychoanalyst.

El autor es becario del programa UBACyT, de la universidad de Buenos Aires (Argentina), donde prepara su tesis doctoral sobre la historia de la noción de trauma y sus usos en historiografía. Da también clases de historia de la psicología. Autor de numerosos artículos sobre la historia del psicoanálisis, historiografía e historia del pasado reciente, es además psicoanalista.

Fecha de recepción: 3 de enero de 2013

Fecha de aceptación: 15 de abril de 2013

Publicado: 15 de junio de 2013

Para citar este artículo: Luis Sanfelippo, “Versiones del trauma: LaCapra, Caruth y Freud”, Historiografías, 5 (enero-junio, 2013): pp. 51-70,

http://www.unizar.es/historiografias/historiografias/numeros/5/sanfelippo.pdf 